Review: Theorizing Film Through Contemporary Art: Expanding Cinema; Jill Murphy and Laura Rascaroli

Sam Thomson

DOI: $10.15664 /$ fcj.v0i18.2278

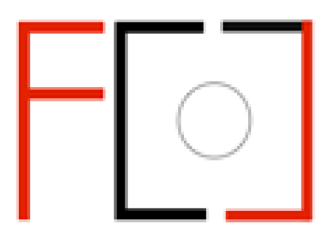

Frames Cinema Journal ISSN 2053-8812

Issue 18 (Jun 2021)

http://www.framescinemajournal.com

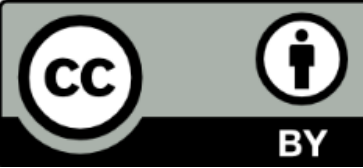




\section{Theorizing Film Through Contemporary Art: Expanding Cinema}

Edited by Jill Murphy and Laura Rascaroli, Amsterdam University Press, 2020

\section{Reviewed by Sam Thomson, University of St Andrews}

In Theorizing Film Through Contemporary Art, editors Jill Murphy and Laura Rascaroli present new ways of thinking about the intricate relationship between cinema and contemporary art. Although this collection fits comfortably among the growing body of literature which seeks to bridge these two distinct worlds, it distinguishes itself from a lot of recent work by asking not how cinema has changed contemporary art, but how contemporary art has changed cinema. The authors within this collection are united by interest in how contemporary art's appropriation of cinema's languages, aesthetics, and structures can contribute to a richer and more nuanced understanding of the medium of film and all work to expand our understanding of how the moving image can be conceptualised.

Part one of the collection, "Materialities", focuses on the physical qualities of the moving image. One of the great pleasures of the moving image's presence within the gallery space is the way in which it forces us to reckon with the material dimensions of the medium. No longer is cinema a distant object on a high-up screen - in the gallery, is it directly before us, in the flesh. Matilde Nardelli, in "Cinema as (In)Visible Object", takes up this most explicitly, placing artists' interest in the materiality of film within the broader context of digital media culture's diminishing physical presence. Works by both Tacita Dean and Elizabeth Price provide the case studies for Alison Butler in "Objects in Time: Artefacts in Artists' Moving Image", where she looks at how differing temporalities emerge from analogue film and digital video respectively, suggesting that each artists" experiments with time work to "rematerialize" the moving image within the gallery space. In the next chapter, Maeve Connolly turns to the actor, a grossly under-examined topic among experimental and artists' moving image scholars. The body itself has always garnered strong interest with the field, but not the labour of those 
participating in bodily performance. Connolly persuasively argues that "the acting body" can offer insight into media production and can "investigate how bodies, data, and memories are mobilized as technologies of storage" (85). Then, Volker Pantenburg's insightful analysis of Gibson + Recoders' work suggests that the artists' "projection performances" foreground the material wonders of the projector, not the images themselves, turning the film into "a framework, a system of light, movement, colour, and, sometimes, sound" (115).

Despite the name, part two, "Immaterialities", is still very much concerned with the material qualities of the moving image, but this section includes a wider historical scope and a more explicit focus on the gallery space. In her chapter, Jill Murphy focuses on William Kentridge's use of pre-cinematic techniques, such as animation and shadow, to consider how we might challenge the image's capacity for representation. She suggests that Kentridge's images" "leanness" allow for a new way of encountering the screen-one that embraces its novelty and its distancing effect (133). Sarah Cooper's reading of Douglas Gordon's Phantom (2011) challenges our sense of the moving image within the gallery, arguing that we ought to see one as an extension of the other, broadening our sense of vision through what we cannot see as much as what we can. Kirstie North turns to Tacita Dean's Section Cinema (2002) to consider how the artist has explored that material and temporal qualities of analogue film in resistance to the trend towards the digital. Chance and fate form the basis of Dean's engagement with Marcel Broothaers' work and to cinema itself, North argues.

The book's third part "Temporalities" concerns itself with how contemporary artworks have challenged or reimagined the traditional modes of time associated with the cinema. Ágnes Pethö, in her chapter, assesses how the "dioramic tableau" absorbs the qualities of both photography and cinema, and suggests that the form allows for a new way of thinking about stillness in relation to cinema (191). Stefano Baschiera looks at Hiroshi Sugimoto's photographical collection Theatres to understand how the work challenges the cinematic 
dispositif in its compressing of a feature length film into a single image. Laura Rascaroli's "Time/Frame: On Cinematic Duration" considers how the frame has contributed to our understanding of art's temporality. Through a diverse range of case studies, including work by Andy Warhol and Stan Douglas, Rascaroli analyses how artists and filmmakers have foregrounded the viewer's sense of time and duration in order to critically engage with the nature of the moving image in relation to other art forms. For instance, Warhol's Empire (1964), she argues, operates like a “(barely) moving painting” (220).

In the collection's final part, “The Future of Images”, Andrew V. Uroskie, Lisa Åkervall, and D. N. Rodowick all consider how advances in new media technology have altered our sense of the moving image and each offer crucial insight into how these changes may configure our sense of the future. Uroskie's analysis of David OReilly's Everything (2017) considers how the form of a video game might allow us to alter how we conceive of a time beyond the Anthropocene, to a world without the human subject. Åkervall considers what happens to the frame of the image in a post-cinematic world. Her analysis of Camille Henrot's installation Gross Fatigue (2013) and Kevin B. Lee's online video essay work demonstrate a diversity of ways in which the frame can be reconceived outside of the movie theatre. In the final chapter of the volume, Rodowick argues that modern art's goal to "release the image from representation" faces new challenges within contemporary art's new digital media landscape. Through close alignment with Theodor Adorno's work on aesthetics, Rodowick suggests that we ought to develop new ways of engaging with the crisis of representation in the digital age.

Theorizing Film Through Contemporary Art demonstrates that if we are to better understand the medium of film we must look beyond it, to the ways in which contemporary artists' have remixed, reframed, and reconfigured the moving image in various forms. The authors within this collection propose that we must see the relationship between these two worlds as dialectical, not one-way. Through many of the authors' detailed textual analysis of 
Frames Cinema Journal, Issue 18 (June 2021)

artworks and others' insightful and rigorous theorising, this collection makes a strong and necessary case to reimagine this relationship, providing a crucial intervention into this growing area of study. 